\title{
Missed GP appointments linked to higher risk of death
}

\author{
Philip Wilson professor of primary care and rural health ${ }^{1}$, Ross McQueenie research associate ${ }^{2}$, \\ David Ellis lecturer in computational social science ${ }^{3}$, Andrea Williamson clinical senior university \\ lecturer, undergraduate medical school, general practice and primary care ${ }^{2}$ \\ ${ }^{1}$ Centre for Rural Health, University of Aberdeen, Inverness IV2 3JH, UK; ${ }^{2}$ General Practice and Primary Care, University of Glasgow, Glasgow, \\ UK; ${ }^{3}$ Department of Psychology, Lancaster University, Lancaster, UK
}

Iacobucci points out that missed GP appointments have been the subject of intense political interest, much of it misleading and designed to blame "feckless" patients. ${ }^{1}$ In a recent article in BMC Medicine, we described an extremely strong association between repeatedly missing appointments and a greatly increased risk of mortality independent of the presence of known long term conditions. ${ }^{2}$ These findings persist after correcting for the number of appointments made. Around $5 \%$ of patients who missed more than two appointments a year over a three year period had died within a year of follow-up.

The increased risk of all cause mortality shows a dose based response with increasing number of missed appointments. Patients with long term mental health conditions who missed more than two appointments a year were over eight times more likely to die (all cause mortality) than were those who missed no appointments. These patients died prematurely, commonly from non-natural external factors such as suicide.
Missed appointments are a major risk marker for all cause mortality, particularly in patients with mental health conditions. For these patients, existing primary healthcare appointment systems may be ineffective. Clinicians (and politicians) should carefully consider the causes of repeated missed appointments rather than ascribing blame.

Competing interests: None declared.

lacobucci G. Sixty seconds on ... missed GP appointments. BMJ 2019;364:169. 10.1136/bmj.169 30609997

2 McQueenie R, Ellis DA, McConnachie A, Wilson P, Williamson AE. Morbidity, mortality and missed appointments in healthcare: a national retrospective data linkage study. BMC Med 2019;17:2. 10.1186/s12916-018-1234-0 30630493

Published by the BMJ Publishing Group Limited. For permission to use (where not already granted under a licence) please go to http://group.bmj.com/group/rights-licensing/ permissions 